\title{
An Urban Oasis Turned into a Concrete Monster
}

\author{
Javaria Manzoor Shaikh \\ Indus Valley School of Art and Architecture, Clifton Karachi, Hanyang University Korea \\ *Corresponding Author: javeria@hanyang.ac.kr
}

Copyright (C) 2014 Horizon Research Publishing All rights reserved.

\begin{abstract}
This paper revolves around the core theme of urban spines alone residential neighborhood, located in mega city Karachi of Pakistan. The set of sites are located in the heart of the city Karachi on M. A. Jinnah Road which is a densely populated area. The solo green space which is the site is surrounded by concrete monster like buildings. This is a four acre land full of thirty three huge, well sculptured trees located near the junction of the busiest areas like Saddar, Garden, Eidh Gah and Jubilee. This site was acting as lungs for the surrounding residents. The population within one kilometer of the site is almost 6,000 people and the residing neighbor belongs to diverse ethnicity. This whole population is apartment dwellers, and these apartments are not very well designed, they are dark, devoid of sunlight and fresh air. In absence of proper sanitation system, and no open space at all for children to play, on top of all the balconies open up to the busy main road of M.A Jinnah. The trees present on the site were not ordinary once they were extremely rear, and most of them were half a century old, beautiful and precious. They can never be grown their ever again due to exhausting pollution and over population. In 2009 this site has been completely bulldozed so that it could be replaced by a humongous concrete block. The area is too congested and the residents were in desperate need a breather there. But yet another pair of lungs was brutally destroyed by a developer who chopped off all the trees. Can one continue killing all the trees in Karachi and hope that we will still be left with room to breathe? If we continued this massacre at this rate, we are going to end up living in a dustbowl with concrete high-rise all around and not even a single plant in sight. Architecture of residential unit lack experimentation and research for improvement, the new technology is being avoided to use, since the constructor feels a threat of failure, our society avoids using new systems and techniques, it our job as an architect to educate client and coordinate with engineers, and go beyond designing good space, and encourage new techniques of construction.
\end{abstract}

Keywords Trees Massacre, Urban Oasis, Karachi

\section{Introduction}

Everyone has a picture in their mind for a perfect home. It is a building type, which is constantly in use; it is inhabited 24 hours a day and 12 months a year. It is a place, which is independent of age factor; people of all age groups live here, from the working man, to the school going kid, to the housewife, to a newly married couple, as well as the college going girl. On the other hand a home, which incorporates all kind of activities for example cooking, dinning, sleeping, working, studying, kids playing, to entertaining of guests, watching television, listening to music, washing and bathing as well as storing space. Above all if these is the emotional activity of love and intimacy between married couples, family members etc.

Hence a home is a building type, which satisfies a wide range of functions, as well as accommodates its users, which are of varying age groups with different requirements. People from different classes, either from a lower income group or a very high-income group, spend almost $50 \%$ of their income into making and maintaining his house.

Providing psychological pleasing spaces: Home good or poor, has a deep and lasting effect on all of us. First we find a shelter to satisfy our needs. This shelter, in turn affects the way we feel and act. Home is our microenvironment. It is just one part of our total environment; house has a great effect on one's life-style and one's personal development. Whether one lives alone or with other persons, one interacts with house. Ones house affect the way one behaves and feel. At the same time, ones style living affects ones home.

Circulation: Minimum walking area and maximum provision of views in that walk for the person walking to go from one place to another, presence of pleasant spaces to give the dweller an opportunity to enjoy the home. Avoiding the use of boring spaces and monotony in planning.

\section{Materials and Methods}

Redefining the concept of intelligence for Pakistan:

The question arises: Being in Pakistan do we actually have the money to built intelligent building? Do we need intelligent architecture in Pakistan? The answer is we need intelligent architecture more than any other place. Because the problem is, we don't have money; the architecture in Pakistan is just restricted to the rich people. No architect design for the poor. 
Secondly we need to consider Recycling water: reusing gray water for watering plants and flushing the waste away. Reusing materials: recycles material Using solar energy Wind energy: to generate electricity on a smaller scale. Since we have a deficiency of water and electricity, intelligence is used here to solve our problems. That is economics and essential requirements. Those are wind, water, fire and earth. In terms of ventilation in building, water for cleanliness and drinking, fire for cooking and earth for planting and greenery.

Hierarchy from public to private: The planning should incorporate the innate quality of human being of very private activity as well as public activities. Hence the home should be planed such, to house and allow the private activity to take place in a comfortable environment, as well as the pubic interaction that is family interaction area should also be planned in an area where there is a presence of a small function.

A builder once stated his personal philosophy about the apartment: "I am a manufacturer of apartment. I give the people what they want within the limits of what they are willing to spend. I always try to stay ahead of my competition. The apartment is a product, like a suit of clothes or a piece of furniture."

But the truth is, an apartment cannot be compared to a suit of clothes or a piece of furniture, which is much temporary then a house and is used by either a single person or a two, and it performs a just one function.

Like any home, the apartment is the background for a series of emotional experiences. It should be a relaxing haven from the tension of earning a living, from noise and worry and strain. It should provide beauty, convenience, security, and privacy for the family living in it. A home is a centre of social life; a place of health, comfort and happiness of the entire family in all the stages and condition of life. Hence in order to merit the title of HOME, it must provide adequately for the following life activity of a typical karachiet's family.

\section{Function Space Allocated}

1. Cooking in an apartment $10 \%$ of the space is dedicated for the cooking of the food, this space should be well ventilated. Food is cooked thrice a day usually.

2. Dining Morning tea kitchen or dining School children hurried meals kitchen Family meals parties dining room Small drawing room

3. Rest and relaxation. Conversation lounge or dining room, News and other light reading, TV lounge or dining room Afternoon tea living room or dining room. Sleeping bed rooms. Study Children's home work dining room or living room.

Doing work brought home from office bedroom Serious reading bedroom. Child-play Confined -as in the case of babies dining room or living room. Free -as in the case of grown up children roof terrace of play area in compound.
Storage . Over hang storage space usually known as dochati used commonly in apartment Cupboards: wall cupboards for cloths in bedrooms. Balconies small size balconies are also usually used as storage spaces.

Concentration: Thinking balcony or dining. Praying bedroom or drawing room. Recreation listening to music drawing or living room Watching television TV lounge or living room. Toileting: General make up bedroom Bath room one or more it's a small room $10 \%$ of the apartment next to the kitchen to sharing the plumbing and ventilation shaft, or can be planned next to the bedroom. WC next to the bathroom, or can be inside the bathroom. Drying cloths terrace or balcony. Entering and leaving apartment. An apartment is a place which can be locked up by one door, or maximum two.

Balcony:

The balcony or a terrace is a very useful space in an apartment. Beside the regular good weather lounging, the balcony is useful as a place to put children cycles and toys, a place to keeps some pats like a parrot on occasion, a place where plants and flowers can grow. It acts as an extension of the room and hence gives an effect of more space. It also serves as a transition from indoor to outdoor. Here the balconies are made really tight and are usually closed to be used as a storage space, or used as drying cloths space. It is considered as a place to collect dust and dirt, specially the apartments with ac it is considered as an unnecessary space.

It can be used as a very pleasant space but unfortunately our builders and constructors designed such tight balconies that it cannot be used I a proper way.

\subsection{Kitchen}

The kitchen is the most important thing in the whole house, because, on the cleanliness and the quality of the food that is prepared therein. The mistress or the maid standing in the center of the small kitchen can reach the various apparatus arranges round the walls on tops and tables and in rows of cabinets provided with trays, drawers and shelves.

It requires the chulla range to be installed as a higher level which allows easy draught of air to blow across for ventilation.

Although a dining area may be provided elsewhere, eating space in the kitchen is desirable for easy housekeeping. It can be used for breakfast, for child feeding, for snacks, and also can double as a place to serve.

The kitchen is one area that must appeal to the women, and rightfully. The apartment kitchen has progressed from the small, sterile laboratory to the more spacious "living room" kitchen.

\subsection{Dining Space}

Primarily dining space can be planned as a part of another room such as a living room or kitchen, or it may be a separate space such that is dining room. Unless eating space in the kitchen is of sufficient size, the kitchen cannot be considered 
as a substitute for a dining room.

A square space is scarcely suited for dining. The floor should have a very smooth and non absorbent surface capable of being easily washed. In an apartment dining room serves many useful purpose. It is the place where children can do the homework, and mother can cut the vegetable. Hence it is desirable that it should be well-lighted and ventilated and should command a good aspect.

\subsection{Bathroom}

The bathroom, like the kitchen, has d3veloped from a mechanically functional room into a warm decorative space with emphasis on efficiency. Within a limited space there is a bathtub or install shower, a basin, a water closet, a cabinet accessories and fittings. All these elements contribute to the overall decorative effects.

The bathroom is one place where privacy is mandatory. Because bathroom is often placed back to back for plumbing economy, they should be treated for sound control. Since there are a lot of elements in a small space, the problem is to keep the total design simple and unified. Besides fixtures and the accessories mentioned, there are such elements as mirror, corner shelf at suitable place for keeping a soapbox, a towel rack, hooks or a set of pegs for clothing to complete the bathroom.

In the case when the bathroom is attached to every bedroom in a luxury apartment, the door should be carefully arranged that when open, it should screen the place where actual bath is taken.

There should be a presence of a ventilator or a small window at a height of six and a half feet with frosted glass shatters, for admitting light and maintaining privacy.

\subsection{Living Room}

Living room as the name says it all is the most liven in room in an apartment and is considered the most important. Living room has many varied activities, some quite, some not so quiet. They may include normal lounging, conversation, reading, study, entertaining, music, and sometime dining. In laying out this room and determining its size, fenestration, and wall space, these living functions are the foremost consideration mostly in apartment drawing room and living rooms are the same. But in recent apartment a separate small drawing room is designed which is used as a reception rooms for guest and for holding social functions.

Essentially a living room is the room of relaxation; it should be well ventilated and lighted with large windows. The living room, like a stage set of a play, is always in full view to everyone entering the apartment. It is human and natural that woman of the apartment should want this room to be as impressive as possible, even though

Broadly used the term "Housing" is synonymous with human settlement and is defined as the sum-total of physical facilities essential to the development of a harmonious, healthy and happy community life.
House is a place where people live. It is valuable in more ways than one. Firstly it provides protection to its residents, prom weather natural calamities and violence. It meets the need of human being. It also provides privacy, becomes a center of attachment and affection in family living, which is then referred to as a home.

Karachi Development Authority defines medium-rise apartment building as ground plus four. Beyond that level by law requires in higher apartment block provision of an elevator. Middle-rise apartment are generally preferred to the high-rise housing. It enables families to be close to the ground, so that the mother can keep an eye on children playing out-door. It enables elderly to step out for a bit of recreation without having to climb too many stairs.

This research project focuses on the designing aspect in Karachi apartment homes, which is a builder oriented field. It is severely neglected in terms of aesthetics and architectural qualities. I will be studying the changes in different area in Karachi in the apartment house, for my theses which is an apartment building.

As cost of land rises, and the pressure on urban land in close proximity to work place increases, it is imperative to achieve the great utility out of each square meter built up space. Hence going vertical is the desired form of building, but this has to be done in a more appropriate way then it is happening in present, in Karachi.

Low rise development is more appropriate in our part of region. It is much cheaper in construction, since the cost of the structure is lesser then the high rise, and it enables saving in stairs, lifts and long corridor.

\section{Satisfying Needs and Values}

House can help to satisfy many of our needs and values. In fact house can be adapted to improve nearly every aspect of life.

The basic element whose presence in a residential space can improve the psychological environment of the place:

Provision of safety. Primarily people need to feel secure at home.

Use of sunlight. Human mind has biological response to sunlight. The vitamin D from sunlight improves ones sense of well being. Providing reference to nature. Flowers presence of greenery and views and vistas to outside environment. Use of soothing colors. Biologically some colors such as red are alarming and blue and greens are soothing. But many colors have specific cultural meaning, which is regional response. Incorporating curved gesture. The corners sharpness if softened it will affect the brain in better way. Providing a place to congregate and share feelings. A space that encourages communication and understanding. Provide for privacy: a place to create, a place for intimacy and passion. Provide a place to dream, pray, reflect or meditate. A place of peace, comfort and relaxationa soft place to relax ones bones. A place to sleep. Provide for the need of the environment to reflect ones status or the 
status that one wishes to project. One needs to be seen as stylish and unique individual.

Provide for the need of environment project their values.

A well deigned residential which has psychologically pleasing environment achieves the following objectives.

Keeps one family together physically and emotionally. Increases the sheer amount of physical comfort. Improves communication and understanding among residents. Improves individual productivity and efficiency. Increases group productivity and efficiency. Encourages intimacy and trust between couples. Promotes health. Defines every person's position in the family. Promotes economics self-discipline. Promotes self-determination Sculpt self-concept. Promote bliss and variety and mystery and beauty. 'Home in its most profound form is an attachment to a particular setting, a particular environment... it is a point of departure from which we orient ourselves.'... (Relph) 1976. Hence it is a starting pint of all activities of the day, and it is a place where we go back to. Therefore the day begins from a home and eventually culminates at the home.

\subsection{Sociological Aspect A Home}

Scientific study of human social behavior, as the study of humans in their collective aspect, sociology is concerned with all group activities-, social, educational and religious.

Sociology tries to determine the laws governing human behavior in social contexts; it is sometimes distinguished as a general social science from the special social sciences.

In the house design the most important thing is to consider the sociological aspect of the life of people occupying the house. To understand the role of the husband, wife, children, grand parent, servant and guests. The most important governing aspect for a better designed residential space is the complete analysis of the routine of every individual of the family.

There are many social problems regarding the design of a residential space, for example positioning of the kitchen and bathrooms, poorly designed air circulation system can cause serious problems in ventilating the cooking smoke, and constant unhygienic smell in the air. The axis of the private rooms in the view of the servant and the guest is also a major issue in our culture. The most important cultural zones in a house are divided into three categories, family, guest and servant. As the category of the person change the attitude of behavior change, the way one talks, the way one treats and the way one behaves with these three different categories are totally different, so does the architecture changes for all three. The presence of an elderly also makes a difference in the living style of a family.

Privacy is a very important factor, utter privacy means freedom from being seen or heard by others and freedom from seeing or hearing others.

\subsection{Guest and Visitors Classifications}

Visitors are the people coming to visit for a short time, or may be for couple of houses. There are different categories of visitors, but the two major types in which the visitors are divided are formal and informal visitors. Formal mean knows only to one member of the family, which informal means known to the entire family. The categories of the guests are kin, friends, family friends, acquaintance, work mates and rishta people the most important category in our culture, in a house where there is a presence of young single person, these visitors are always invited. This is the reason for a present of a most formal guest entertaining space which is commonly known as a drawing room.

The formal guest is taken to the drawing room and if they accompany a female they may then be intermingled with the female of the family, so that she can be entertained, or in some cases there is a segregation so the female can be taken to the family lounge, 9if the formal visitor is relatively stranger to the family, although in some cases women does not observe perdah, but they don't encourage intermingling with the visitors they don't know personally.

Meals and snacks are served by the servant, in case of the rista people visitors, then by the girl whom they are interested in. or other female of the family in a tray or a trolley, to the door of the room where e she knocks or calls out slowly to the men of the family to come and take snacks.

Informal family friends and guests could be taken in the family lounge and children's friends could be taken into their rooms.

Spaces which are used by the formal visitors are kept clean and furnished in the best possible way. The internal and external windows are usually closed and are kept covers by curtains. The decoration and ornamentation reflects one's life style and cultural background. It also enhances the memory of one's older generation's culture by preserving their belongings, and photographs or their achievements memory that can be a degree. This also adds in visual surprises.

\section{Cultural aspect in a House}

Whenever a group of human being comes to live together and settle down at some place then usually their needs requirements eating habits, clothing style information and knowledge level, thoughts happiness and hatred become one because of this unity, their understanding of good or bad also develops. They have the same desire to change of the combined desires on the change brought about by this combines desire to basically the civilization of that group or nation

In the light of the about definition culture thus encompasses the thinking and action of a group of people in the form of a nation it has always been and still is a source of identity for the nation. As shown in Figure 1-10

As the culture is also composed of ideas abs craft it therefore produces products of architecture which becomes the outcome of the culture values and social needs of that group thus culture ad architecture are interrelated 
architecture is the true representation of human culture.

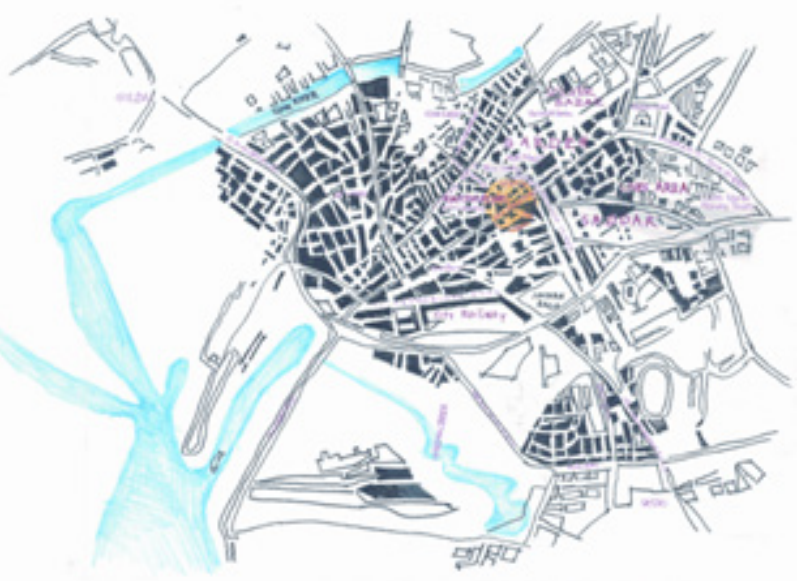

Figure 1. Karachi map showing the massing, the site lies in the most dense urban context.

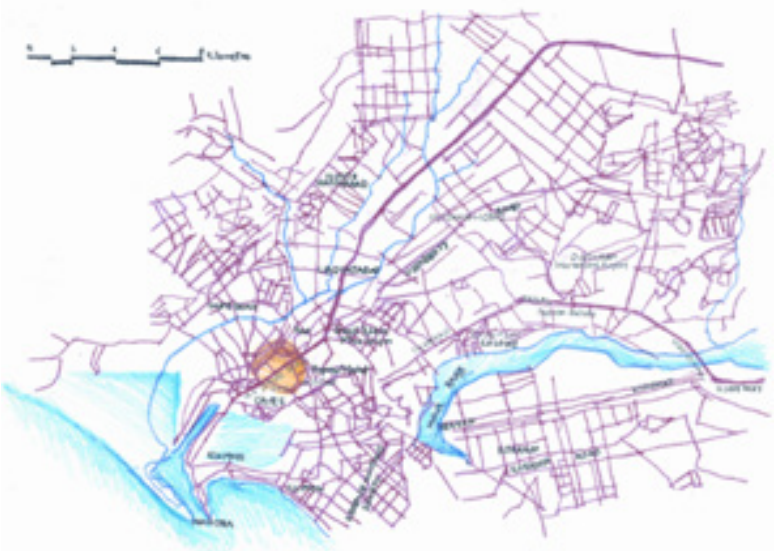

Figure 2. The road network and the relationship to the site, the site hits the most prominent road of Karachi, which acts as a datum which runs through the entire length of Karachi.

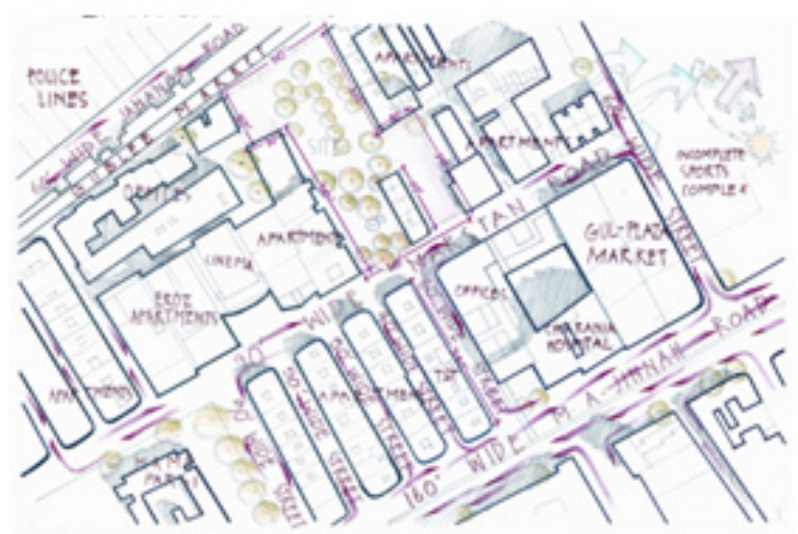

Figure 3. Functional zoning of the area.

Building a house is a cultural phenomenon its form and organization are greatly influenced by the cultural environment or setting to which it belong. In the early recorded time the house becomes more then shelter for primitive man and almost from the beginning function was much more than a physical or utilitarian concept religious ceremonies has almost always preceded and accompanied its foundations and erecting. If provision of shelter is primary function of the house then its secondary purpose is the creation of an environment best suited to the way of life of inhibiters, 'a social unit of space'.

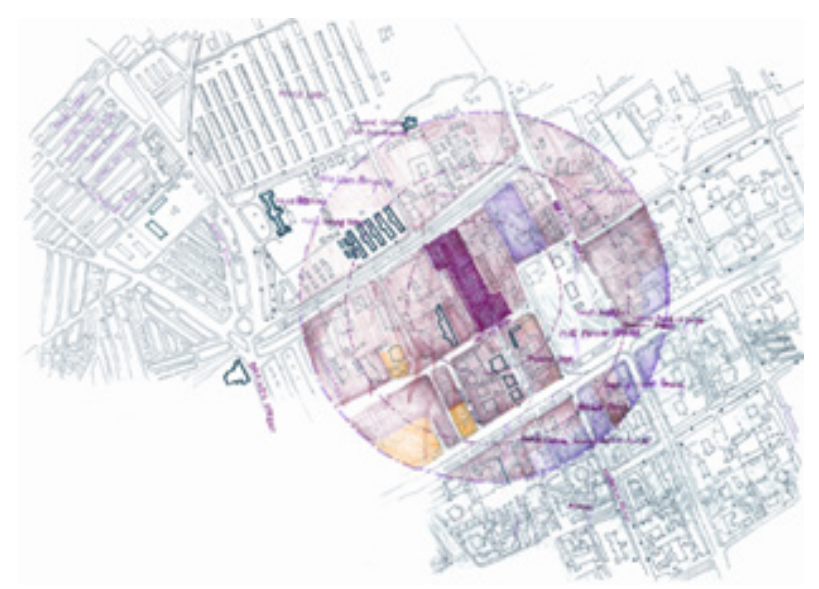

Figure 4. Circumference showing the area which the neighborhood center will be serving.

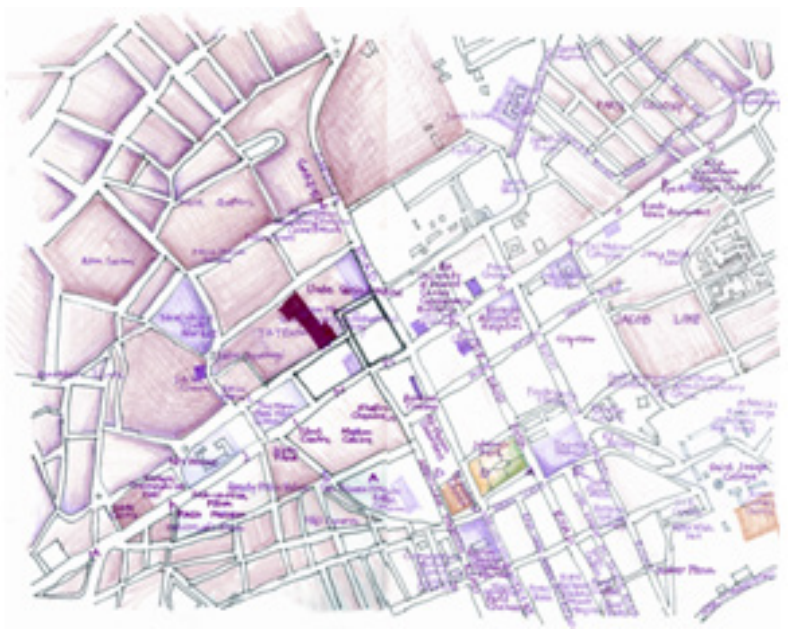

Figure 5. Karachi map showing the massing, the site lies in the most dense urban context. Contextual analysis

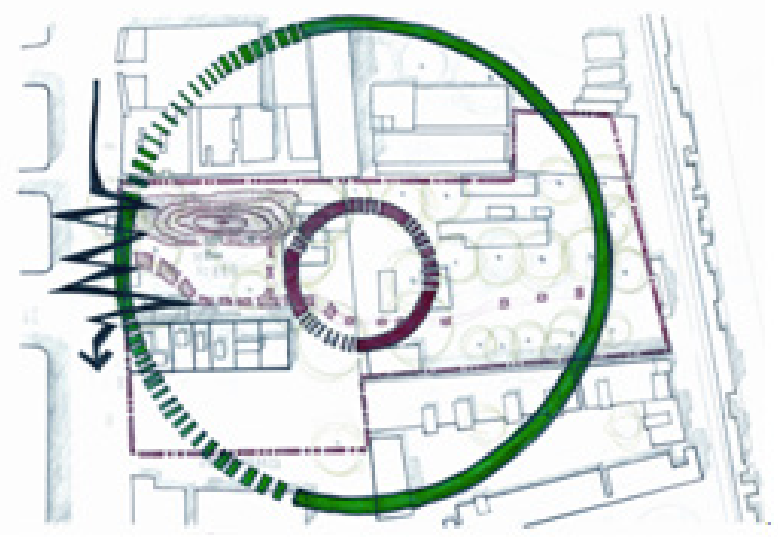

Figure 6. The site and the surrounding environment 


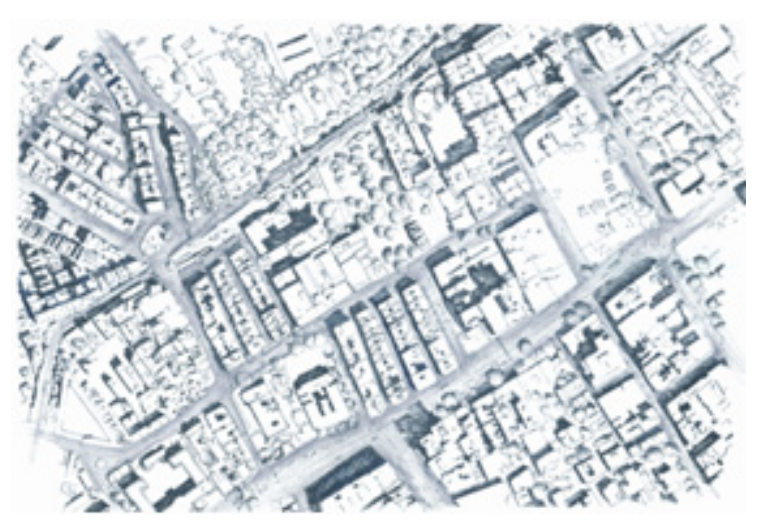

Figure 7. The Google image showing the plan of the site

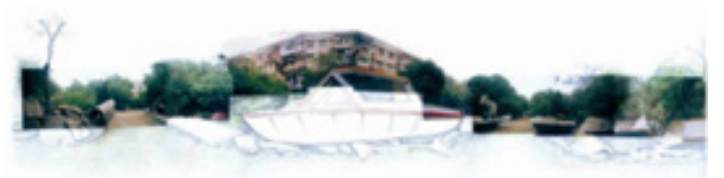

Figure 8. The site used as a junk yard

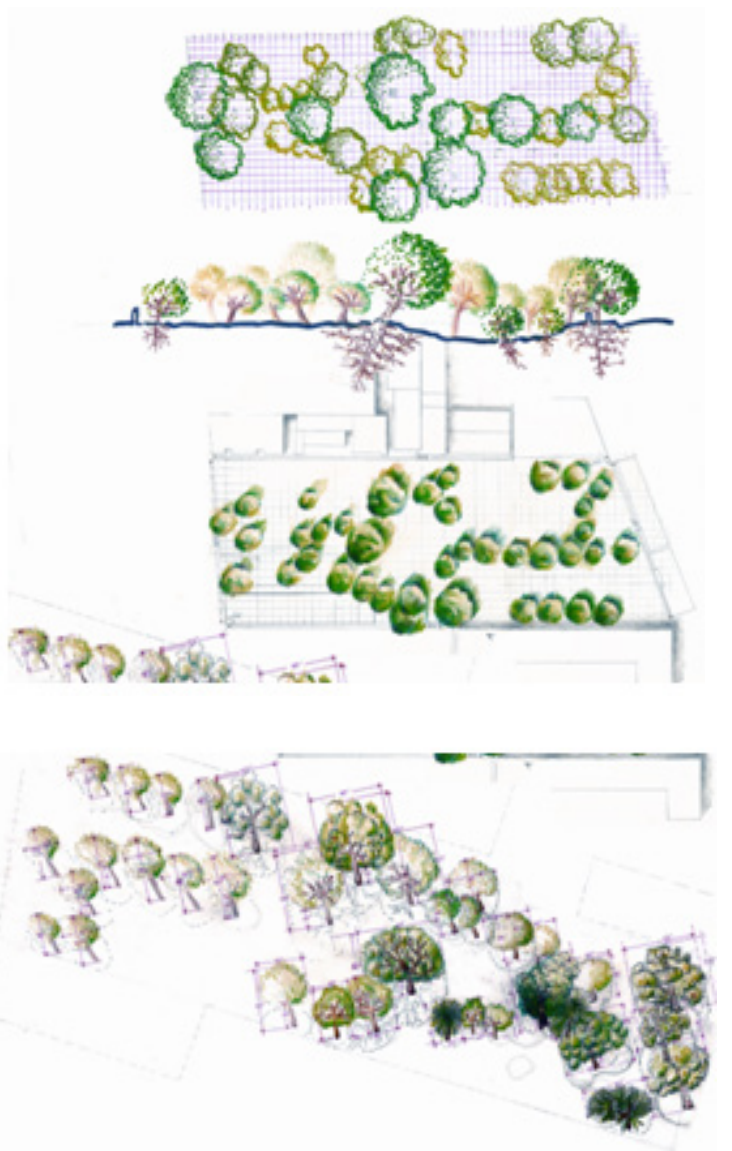

Figure 9. Trees dimension on the site

Hence a house is a building type which manifests the complex interaction of many factors. Which can broadly be taken as social, cultural, ritual, economic and physical shelter, no doubt, is a basic need but as soon as the shelter is erected, it becomes private and owned by a family. This gives rise to privacy and territoriality, interrelating and resulting in the creation and reflection of culture.

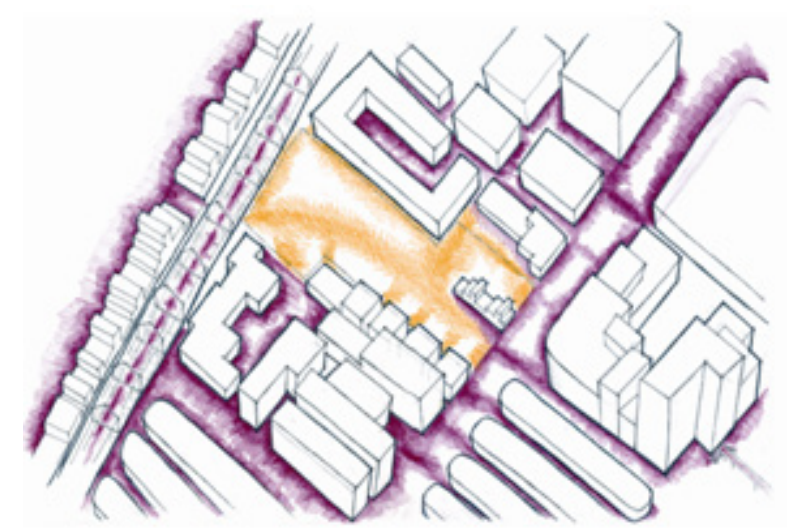

Noise to the site, views into the site and from the site and circulation pedestrian

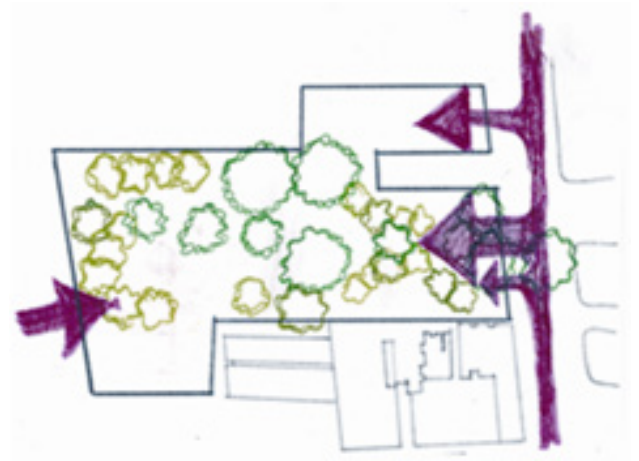

Figure 10. Organization of 33 trees, on an H- shaped site
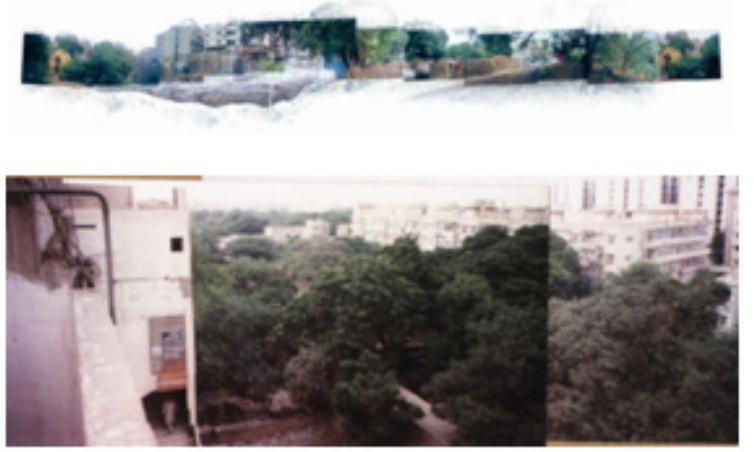

Figure 11. Tree dimension and Karachi city population, according to the voting of the area.

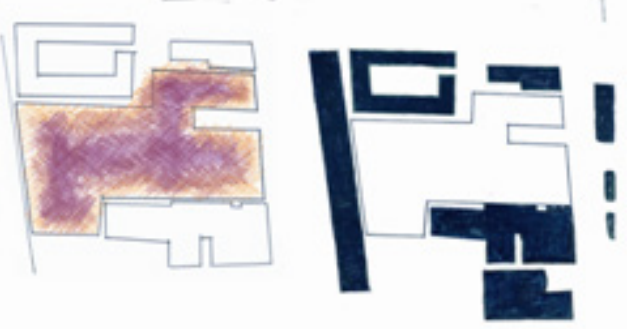

Figure 12. M.A. Jinnah Road the spine of the city near which the site is located, views of the site Present condition of the site, solid void and a study of site shape spaces 

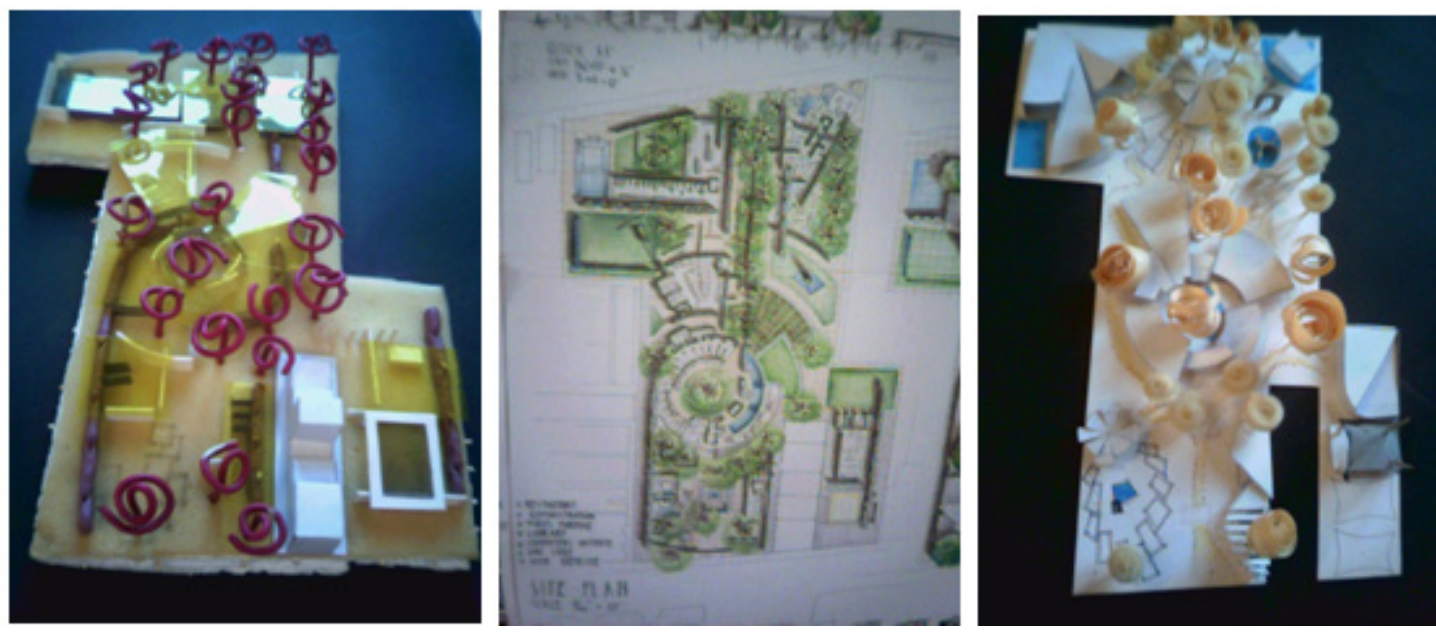

Figure 13. Model and planning of the site
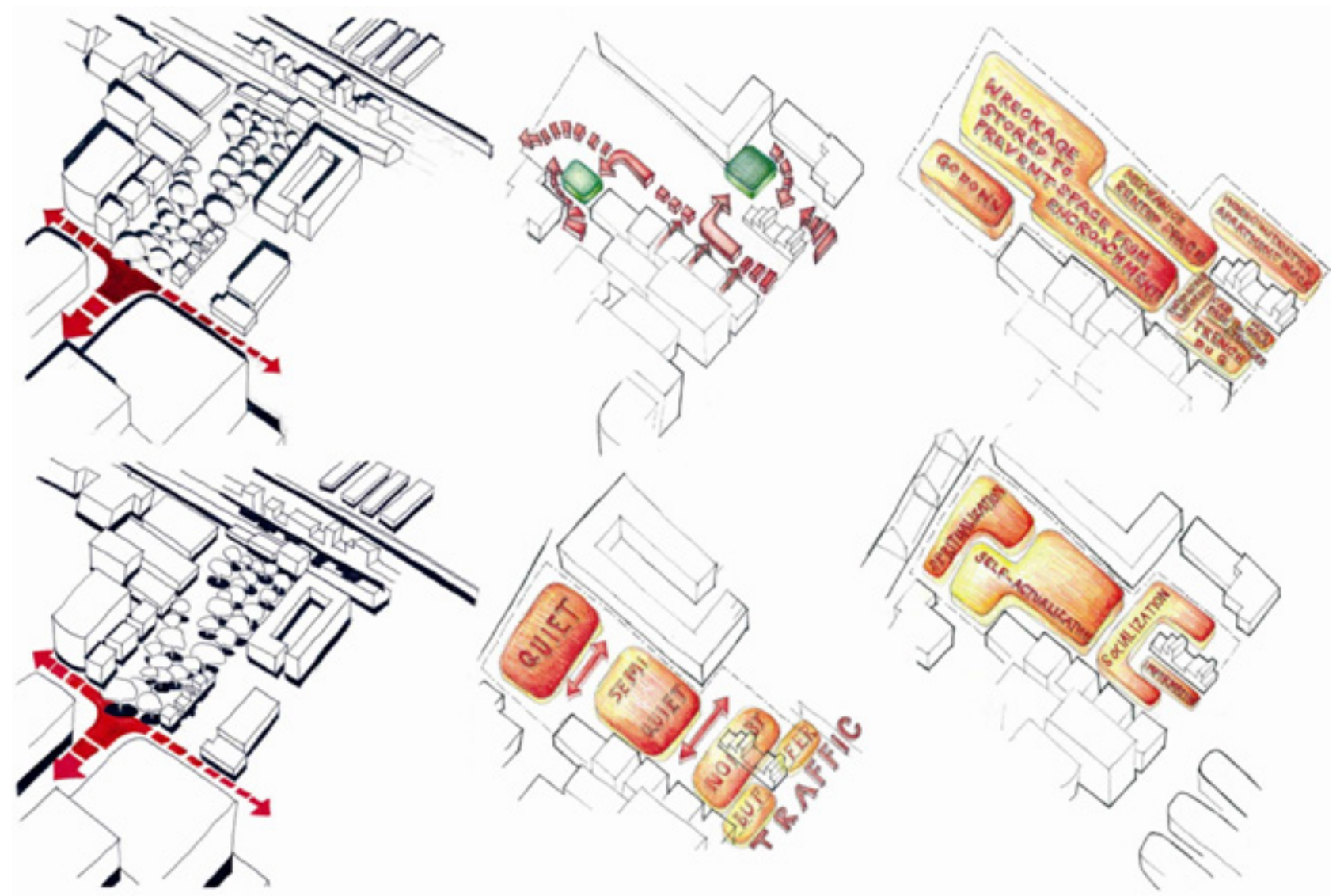

Figure 14. looking into the site

Shadow study in evening and morning times, proposed circulation pattern, and bubble diagrams, present situation and proposed division of Shade and shadows on the site, schematic designs and bubble diagrams 

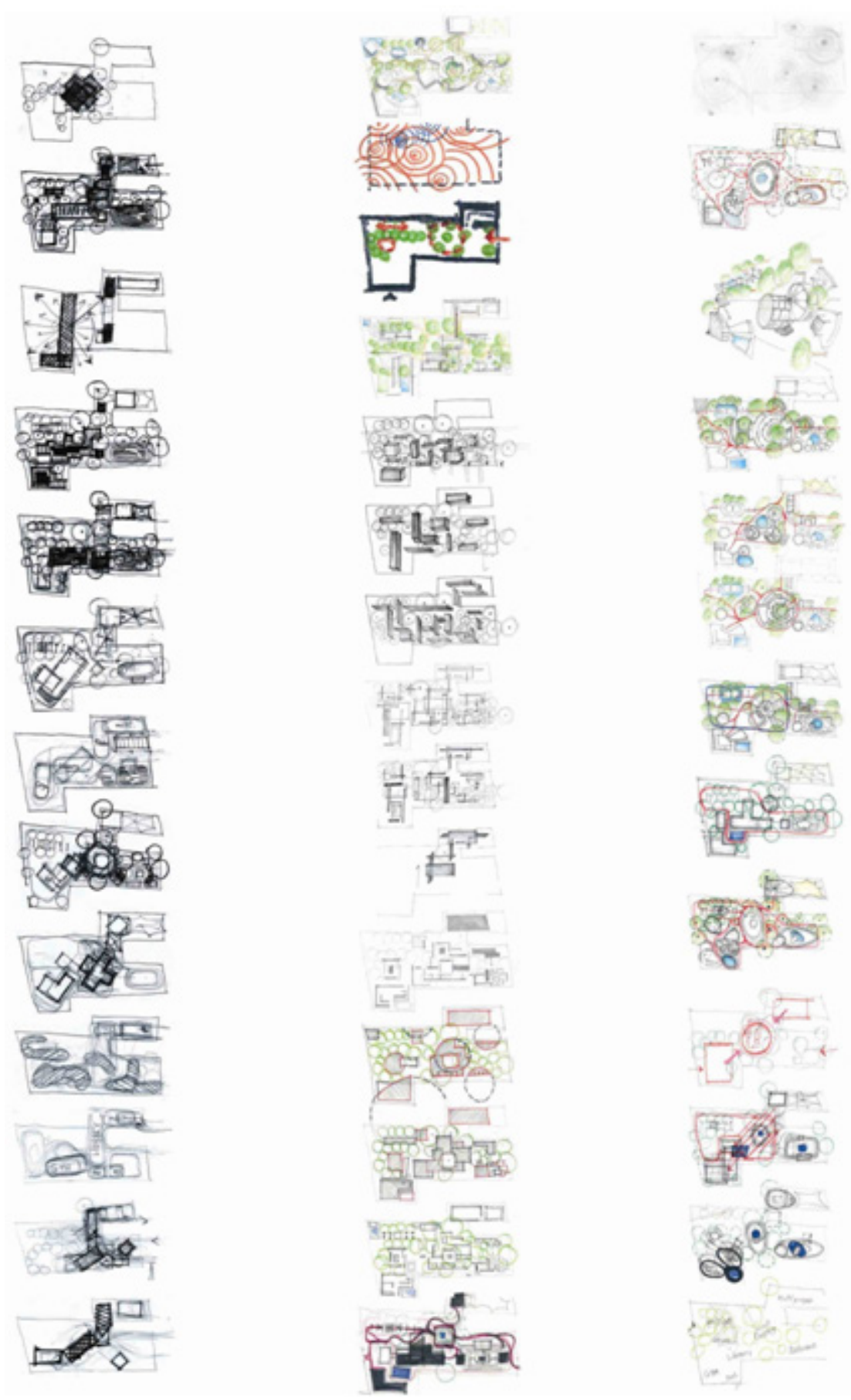

Figure 15. Evolution of design 


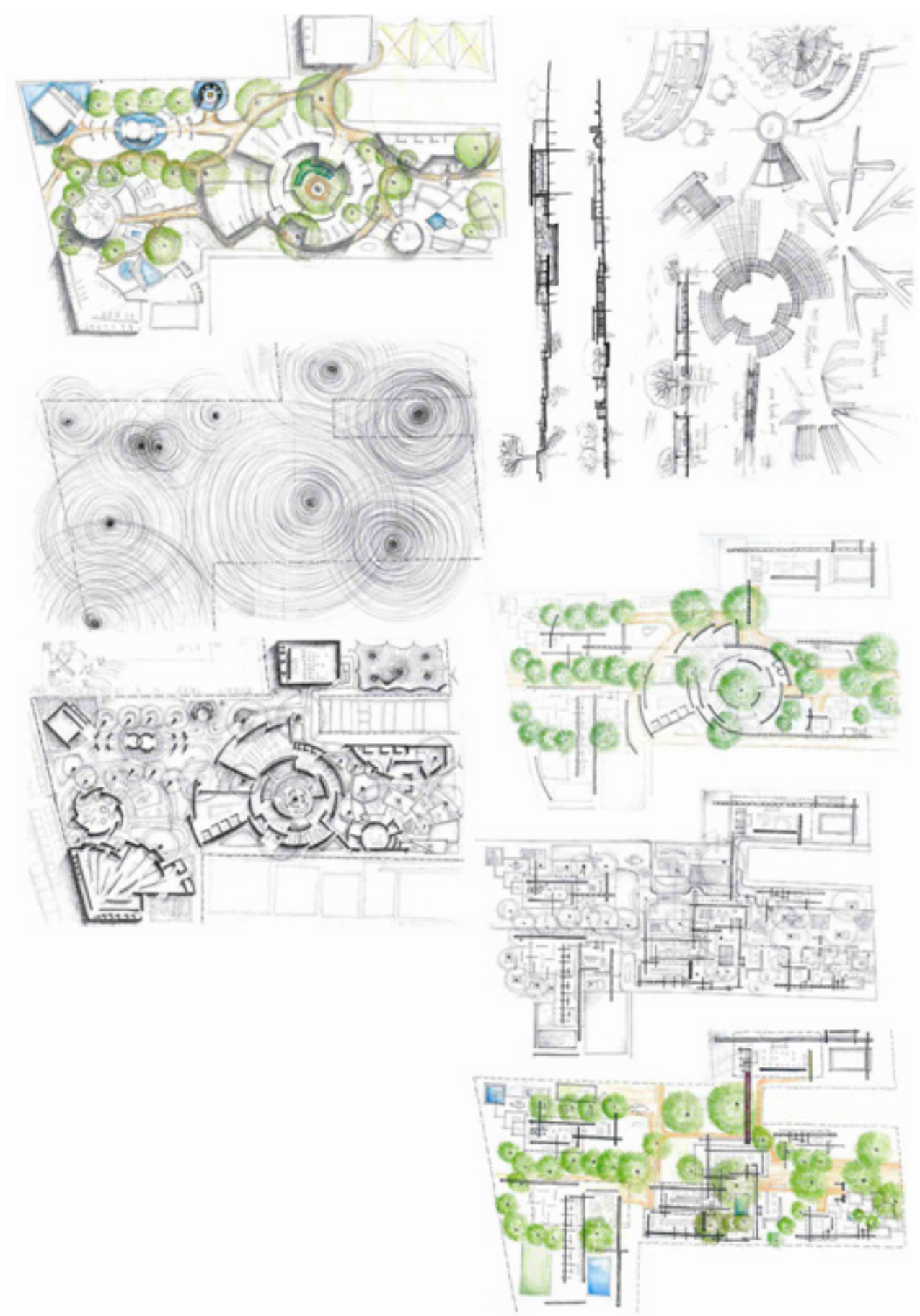

Figure 16. Planning maps plan 


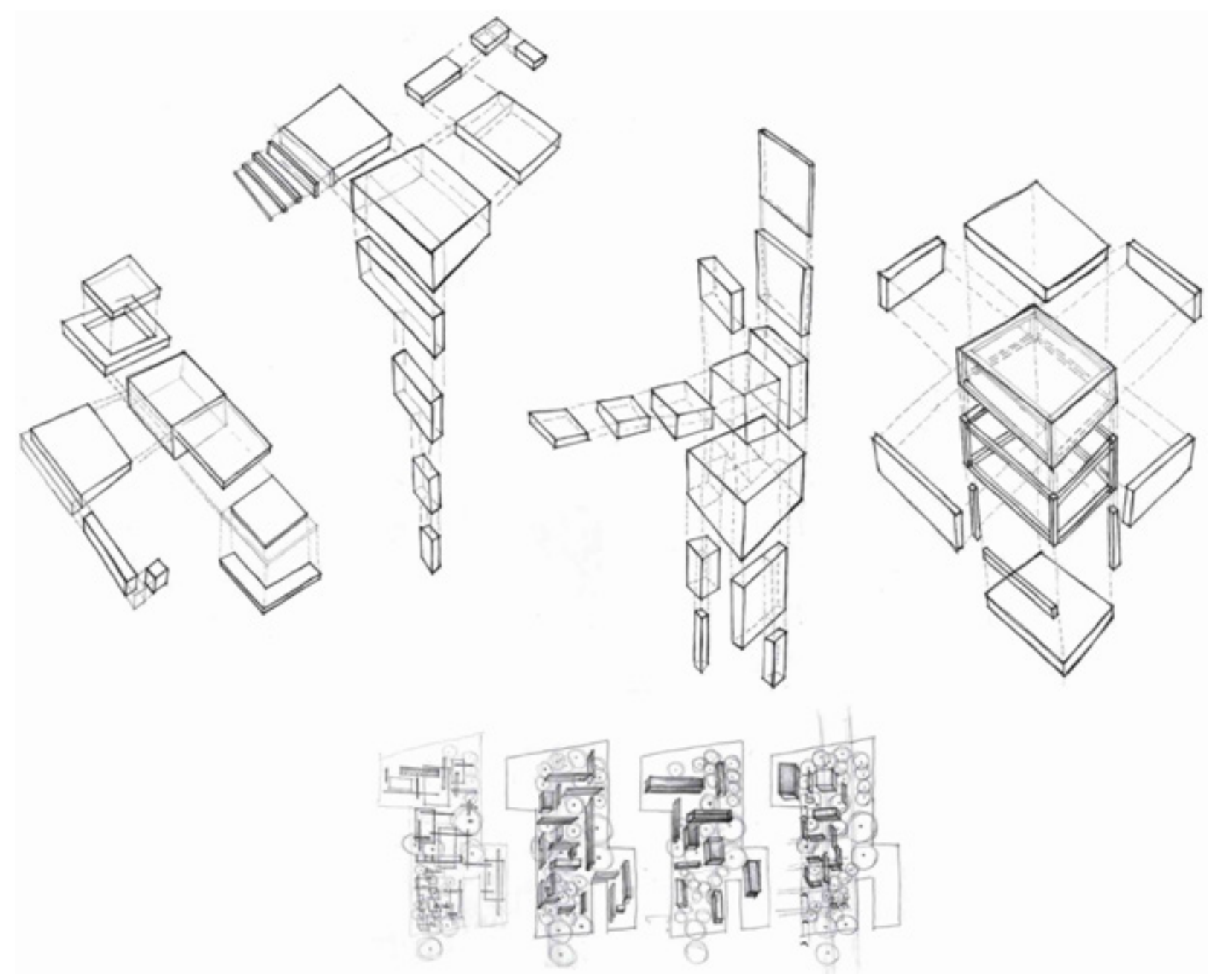

Figure 17. Concept: destruction of the box

\section{Planning}

Figure 1 to 17 shows the bellow planning

1. Bubble diagram

2. functional zoning

3. area shaded

4. area available to built rest have trees

5. possible configuration on the basis of maximum square footage

6. three dimensional sketch

7. three dimension configuration

8. material difference

9. on site location

10. functional layout

11. schematic design

12. green areas celebrated

13. three dimensional view of schematic design

14. design development

15. incorporation of wind tunnel

16. development

17. sectional functional zoning

18. detail of model of the precedence study

19. overview of model of the precedence study

20. section of the precedence study
21. plan of the precedence study

22. use of levels in section

23. air movement study in section

24. air circulation pattern

25. air suction

26. precedence study drawings

27. evolution of the eco house a model study

28. development of the mass

29. skewing and transformation

30. derivation from a square

\section{Massacred Trees}

Taking away life is not a big deal in out society, especially in Karachi, killing trees is not even a crime here. Or even if it is then it's the minutest of all.

A four acre patch of land, full of thirty three huge, well sculptured trees, in the middle of the Karachi city, near the junction of Saddar, Garden, Eidh Gah and Jubilee. This green patch was acting as lungs for the surrounding apartment dwellers, belonging to different ethnic groups. Recently has been completely bulldozed to be replaced by a humongous concrete yet another block. 
These trees were not ordinary once they were extremely rear, most of them were half a century old, beautiful and precious trees. Which can never be grown their ever again their due to exhausting pollution and over population.

Table 1. The population within one kilometer of the around the site is almost 6,000 almost all of them are apartment dwellers, and these apartments are not very pleasant homes.

\begin{tabular}{|c|c|c|c|}
\hline Population & Male & Female & Total \\
\hline Muslim & 2647 & 2505 & 5152 \\
\hline Christen & 201 & 222 & 423 \\
\hline Hindu & 36 & 26 & 62 \\
\hline Parsi & 102 & 82 & 184 \\
\hline Total & 2986 & 2835 & 5821 \\
\hline
\end{tabular}

Table 2. the questionnaire replies for the facilities

\begin{tabular}{|c|c|}
\hline Facilities required & votes per 100 \\
\hline Library & 54 \\
\hline Prayer area & 34 \\
\hline Computer center & 44 \\
\hline Tuition center & 39 \\
\hline Restaurant & 32 \\
\hline Jogging track & 38 \\
\hline Multipurpose & 21 \\
\hline Garden space & 37 \\
\hline Play area for kids & 35 \\
\hline Flower shop & 28 \\
\hline
\end{tabular}

A home can be described as, " $a$ world within the world" where one goes back to. To understand the world; it is a breather. Every individual's relaxing place, where one belongs, here the family gathers in the evening. Discussing the day; it is a multi-purpose space, beyond this home is also housing a lot of other complex activities (e.g. eating, sleeping, talking, studying and intimate practices). A person feels fresh here and he gains confidence.

Hence home is a form of building type which is used by almost every person, in the world and it is a place where a person is mostly associated to, i.e. it is used the most in the life time, therefore one can say that; if sleeping included then; an average person spend up to $50 \%$ to $30 \%$ of his entire life in his house. Hence in this dissertation it is supposed that home is a place which sculpts human behavior.

"Residential environments mean different things to different people.... It's a citadel that provides privacy.... A heaven from an often hostile, complex, and competitive world ..... a showcase for a lifestyle that is to be shared with outsiders ....... whatever its desired function and attributes, a residence should sustain its occupant and inspire them in the pursuit of their lives". I
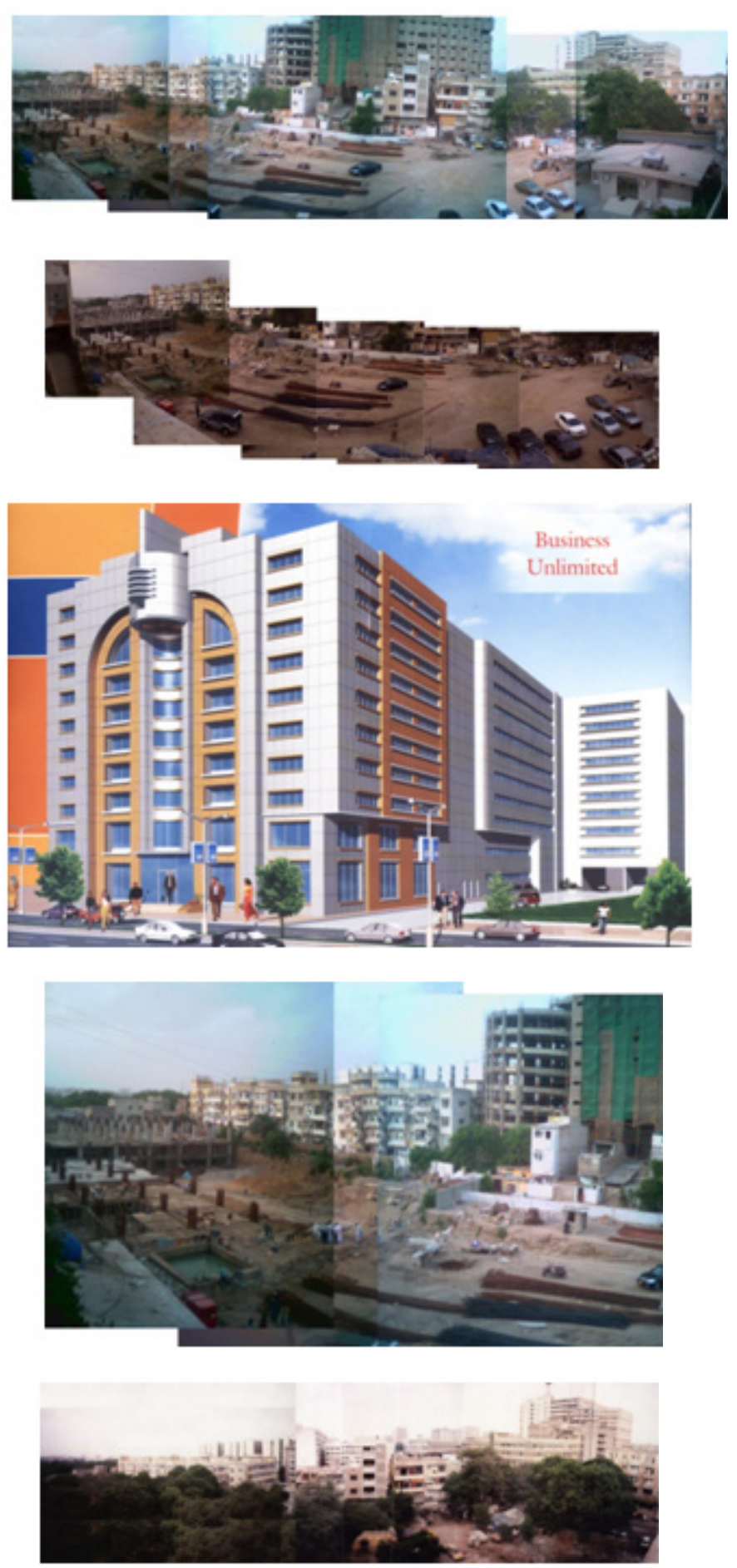

Figure 18. shows the present concrete monster on the site

The area is too congested and over populated. The dwellers upper mentioned expectation were not been fulfilled at all hence desperately needed a breather there. The idea was to use this provided space in a way to fulfill the definition of a home for the residence of the area. When a survey was conducted through a questioner in which they

\footnotetext{
${ }^{1}$ Penny Bonda
} 
were asked to vote for what they want in the site to be the opted as following:

But all the dreams were shattered when a developer came and destroyed the lungs, chopped off all the trees and shattered the poor dwellers dreams away. As shown in Figure 1-16

This design was proposed on the site respecting the trees, to facilitate the residents of the area, on the site shown Figure 5-15

Now this is being made on the site and all the trees are chopped off and a concrete monster will soon appear on the site instead of those beautiful trees.

Initially the site was lush green in the metropolitan city of Karachi, now all the trees are shopped and another concrete block is being built

\section{Conclusions}

\subsection{An Urban Oasis Turned into a Concrete Monster}

Life is not a big deal in Pakistani society, especially in Karachi, killing trees is not even a crime here, and if it is then it's the minutest of all. Karachi is one of the most highly populated cities with $18,000,000$ people living in an area of $3,527 \mathrm{~km}^{2}$ and average of 4,115 persons $/ \mathrm{km}^{2}$. This density increases towards the heart of Karachi which is sadder where there is an average of 5,821 persons $/ \mathrm{km}^{2}$.

The above site located in the heart of the city on M. A. Jinnah Road shows an aerial view of the densely populated area. Clearly indicating one and only green path surrounded by concrete monsters. This is a four acre land full of thirty three huge, well sculptured trees located near the junction of the busiest areas like Saddar, Garden, Eidh Gah and Jubilee. This site was acting as lungs for the surrounding residents. The population within one kilometer of the site is almost 6,000 people and the residing neighbor belongs to diverse ethnicity. This whole population is apartment dwellers, and these apartments are not very well designed, they are dark, devoid of sunlight and fresh air. In absence of proper sanitation system, and no open space at all for children to play, on top of all the balconies open up to the busy main road of M.A Jinnah.

The trees present on the site were not ordinary once they were extremely rear, and most of them were half a century old, beautiful and precious. They can never be grown their ever again due to exhausting pollution and over population. Recently this site has been completely bulldozed so that it could be replaced by a humongous concrete block.

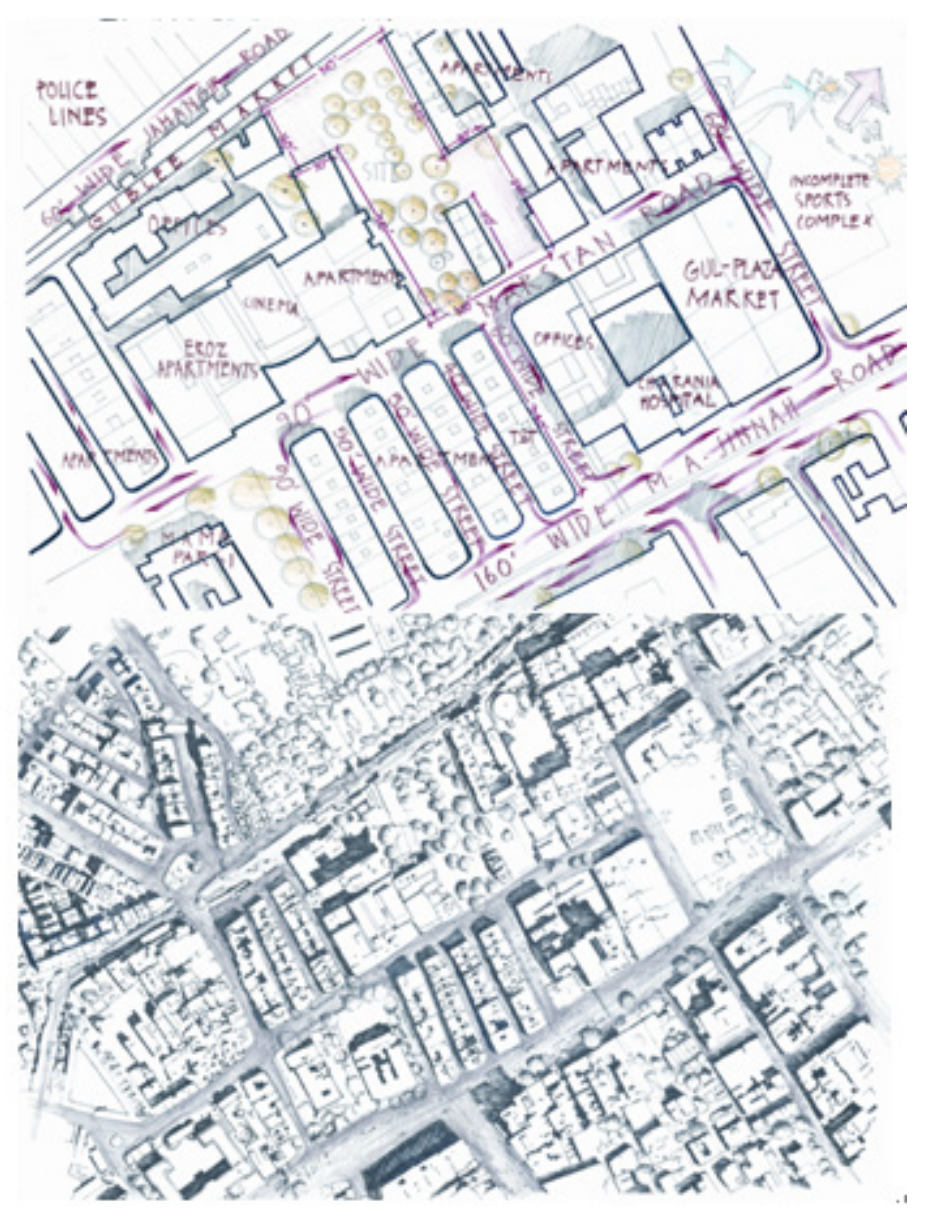



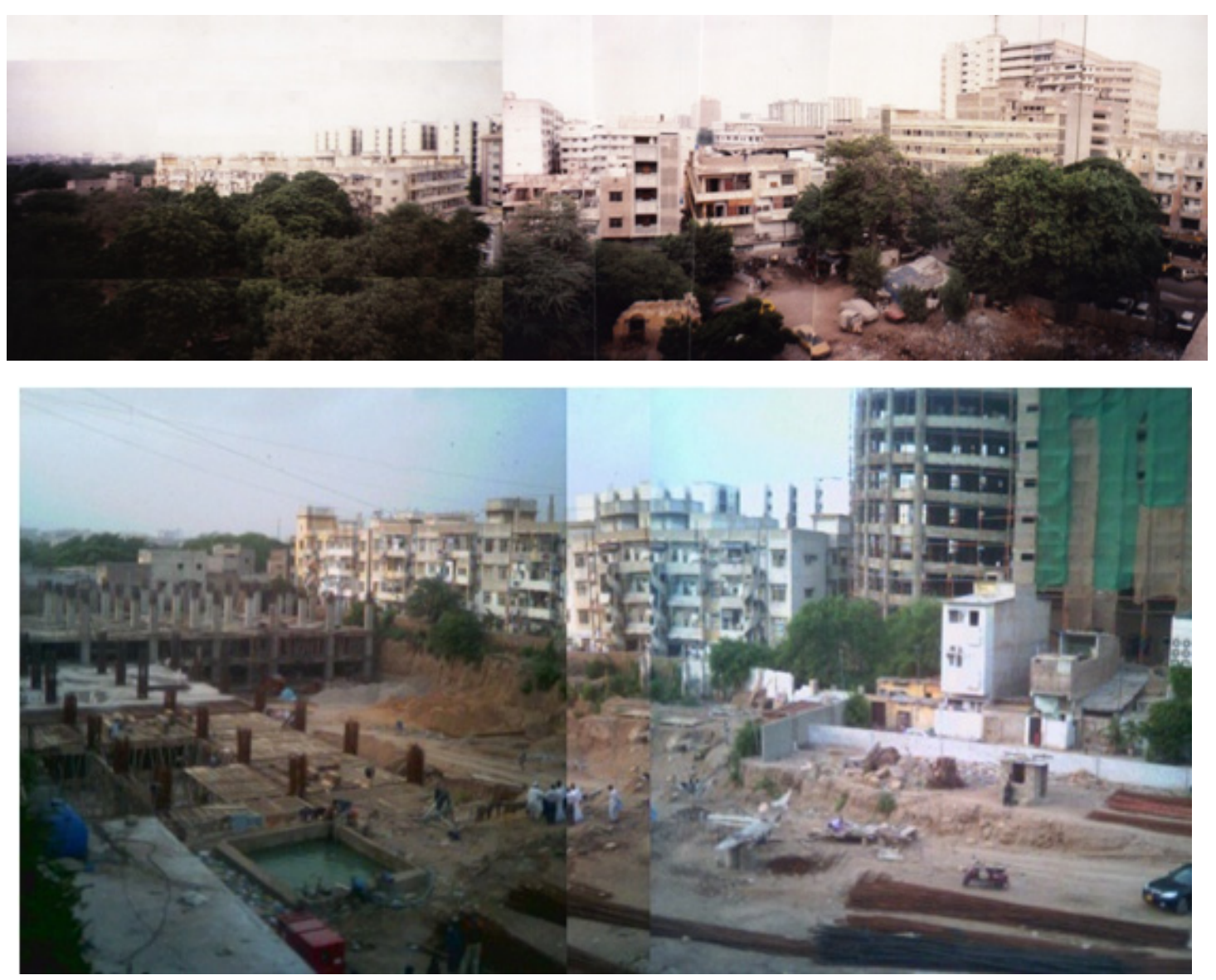

Figure 19. the site plan and photos

The area is too congested and the residents were in desperate need a breather there. But yet another pair of lungs was brutally destroyed by a developer who chopped off all the trees.

Can one continue killing all the trees in Karachi and hope that we will still be left with room to breathe? If we continued this massacre at this rate, we are going to end up living in a dustbowl with concrete high-rise all around and not even a single plant in sight.

But one thinks, when the carnage of $12^{\text {th }}$ May could happen, what's the big deal about chopping down trees? I've often wondered..... Well, at least once anyway.... Why human beings have so little respect for other living things.

May be we have completely lost touch with the softer soul in us. Why does this 'inhumane behavior' in us have such negative connotation when plants are, in actual fact, much nicer than human beings? They don't invade Iraq, take over children's libraries, and blow themselves up in busy market places.

But question remains the same, is this new plan we are seeking for Karachi.

Are we going to build, where ever we find even an inch of a land?

\section{Acknowledgements}

We are very grateful to experts for their appropriate and constructive suggestions and the people who let us enter their houses and fill the questionnaire.

\section{REFERENCES}

[1] Kulle R, Architectural philosophy, Rikard Studentlitteratur, Pennsylvania, 1973

[2] Norberg-Schulz. C, The concept of dwelling, New York, Rizzoli, 1985.

[3] Rohinton E.M An Urban Approach to Climate-Sensitive Design, Spon press ,Glasgow, 2005 Architecture Library University of Seville.

[4] Stephen J. Kirk, Creative Design Decision a systematic approach to problem Solving in Architecture, Van Nostrand Reinhold Company, New York, 1988

[5] Raof. S, Eco house 2 a design guide, Architectural Press, Oxford, 2003, pp 55

[6] 3. Fuller. M, Environmental Control Systems Heating cooling lighting, Mc-Graw Hill Inc, Singapore, 1993, pp 76

[7] Junestrand.S \& Tollmar. K The Dwelling as a Place for Work, The Royal Institute of Technology, Department of Architectural Design and Technology, Sweden, 2003, pp 61

[8] Gaston B, The poetics of space, NewYork, 1995, pp 51 
[9] The national Energy Conservation Center, Design Manual for energy efficient buildings in Pakistan, Enercon, Islamabad, 1990, pp 65

[10] Roaf. S and Fergus. N, Adaptive Standards for Thermal Comfort in Buildings, Heriot Watt University, International
Seminar, Saint John International University, Torino Italy, Sustainablity for building Renovation and Restoration, 2009, pp21

[11] Narenda K. B, Passive Building Design, A handbook of Natural Climate Control, Netherland, 1994, pp 133 